\title{
BRAZIL: TRADITION VERSUS MODERNITY - A LAW, CULTURAL AND EDUCATIONAL PROBLEM
}

\section{BRASIL: TRADIÇÃO VERSUS MODERNIDADE - UM PROBLEMA JURÍDICO, CULTURAL E EDUCACIONAL}

\author{
George Browne Rego ${ }^{1}$
}

Resumo: Este trabalho tem por objeto enfrentar os problemas relacionados com a cultura e as mudanças sociais no Brasil e como eles foram afetados por crenças mais profundas que tenham atuado como barreiras contra o desenvolvimento social e econômico.

Palavras-chave: Gilberto Freire. Educação. Cultura. Direito.

Abstract: This paper is concerned with problems related with culture and social changes in Brazil and how they have been affected by deeply held beliefs which have acted as barriers against social and economic development.

Keywords: Gilberto Freire. Education. Culture. Law.

\section{Introduction}

The aim of this paper will not be one of analyzing the problem chiefly in a formal institutional approach. Rather it will to a great extent be looked on and interpreted through a cultural prism. i.e., how historically individuals and group values affected the national social structure. In other words, how their intentions, will, conduct and prejudices, derived from their historical and cultural origin constituted a strong sedimentation in the Brazilian social life.

In fact, institutional efforts toward promoting social and educational welfare have been innumerable. Abundant literature, both national and international have exhaustively analyzed this matter.

Attempts at passing legislation to promote social-educational changes have been inspired either as a kind of self-consciousness on the part of the Brazilian government or via the emulation of legal procedures adapted or simply borrowed foreign countries or even international rules.

The broadest and deepest experiment in terms of adopting an

\footnotetext{
${ }^{1}$ Doutor em Filosofia do Direito pela Tulane University. Professor visitante da Universidade de Oxford, Reino Unido.
} 
international legislation was the introduction or adaptation of certain principles inspired by the Universal Declaration of Human Rights, which was signed in 1948 by no less than 120 countries throughout the world.

Difficulties in implementing such a legislation were common to all countries, but particularly in the case of the non-developed ones, among which Brazil, under certain aspects, could be classified. It is clear that such a legislation had some indirect legal effects upon the nations which subscribed to it. However, it cannot be seen as a superjurisdiction power binding on the nations and their legislations. These rights, which extend to every memberState-on the grounds of certain political and moral international and national pressures-were not created by the State itself, or through the formal approval of its citizens. Neither are they bestowed with legal penalties on the hypothesis they come to be broken. To what extent then the individuals themselves really accept, believe and are committed to them is something that remains obscure. Moreover, resistances from authoritarian governments to implement such rights are very common because they see the claim of those rights by certain social groups or individuals themselves as an ideological strategy to weaken a centralized dictatorial military control upon society.

All these implications, therefore, transcend the pure institutional interpretation of a society and seem, sometimes, to sink more deeply in the own historical and cultural traditions of a nation, to the deep roots that underlie its inner life and its original social relationships. So if one wants to understand them better one should go beyond their formal and institutional delineations to investigate historically and analytically such roots.

A rather complicated matter that is connected with the problem

is the very concept of social change which is not an easy idea to convey. It may imply and be related to variations and diversifications in physical conditions or, as seems to be more important, to human intentional or even unconscious actions as well. Ecological, including demographic changes, technological changes and political changes form a complex comprising the most important causes of general social change.

Although a formal analysis of the concept of social change is not within the limitations of this paper it seems pertinent to call attention to such complexities when one is studying a country like Brazil. Its intricate problems related to ecology, technological development and political control - as one shall briefly see sometimes appear unsuitable to be explained by conventional theories and analysis, especially those elaborated in and applied to developed countries.

\section{The Background Of The Problem}

Brazil has been undergoing dramatic challenges to promote social reforms on the above tri-dimensional spheres.

A brief introductory sketch comprising geographical, demographical, racial and socio-political information, would help as a preliminary approach to one not familiar with the country, as a first perspective of its potentialities and 
difficulties.

Being the world's fifth largest country in area, it covers nearly half of the South American continent. It is larger than the United States and one of the most wealthy in natural resources in the western hemisphere. Yet, it is one of the poorest in the world in per-capita income, even though the wealth represented by those natural resources is still considerably unexploited. The range of climates varies from equatorial to temperate. With a long coast-line Df 4.604 miles on the Atlantic side, the country displays enormous contrasts between humid jungles and dry plains and mountains. The South an South-East, with only $18 \%$ of the land, concentrate $60 \%$ of the hundred and forty millions of inhabitants, while on the $42 \%$ of the land located on the North the population rate goes only to $5 \%$.

The Brazilian population was originally composed of

Portughese, Indians and Africans. Nevertheless none of these elementary groups was ethnically homogeneous during the first century of the Portuguese colonization. This is not only a peculiar kind of race integration, but mainly the amalgamation of a new culture with own psychological and social behavioral implications. As Oliveira Viana observed:

Within each of these original races their representatives failed to show either morphological or mental unity; on the contrary they varied more or less observably in the one or the other sense, the black and the red races presenting types of such accentuated somatic and psychological diversity, that one might say the members of each group come from races entirely distinct and dissimilar ${ }^{2} . '$

In terms of the geographical distribution of social groups it is not infrequent, still today, that one can find in Brazil a patriarchal-like way of living, coexisting in close proximity with industrialized centers. By the same token, one can also see slums enclaved in the core of luxurious urban areas, plenty of traditional mansions and sophisticated buildings. Contrasts which seem, not rarely, to the eyes of the foreigners, very unusual or even exotic. Such contrasts have often suggested to some visiting social scientists who studied Brazil that they designate it as a land of contrasts or similar epithets which spotlight these contradictions.

The social plasticity or elasticity of the country in living together or in contiguity with different racial, social and economic groups; the possibility of society's absorbing the tensions and pressures of this "social conviviability"-despite today's crescendo level of antagonisms and social conflicts; finally, a still existing tolerance and fusion of races both in sexual relation and economic cooperation (in spite of the existing implicit or explicit ranges of personal and social discriminations) constitute a special trait of the nation, even within the Latin American context. These are special conditions that are explained by some intellectuals as a reminiscence of cultural patterns whose origins go back to the colonial and post-colonial Brazil. Among them Gilberto Freyre - whose ideas we

\footnotetext{
${ }^{2}$ Apud. Robcno, Havighurst.J. et al. Society and Education in Brazil. Univ. of Pittsburgh Press 1965, p. 24
} 
will soon examine - had a pivotal role in explaining these historical cultural patterns and their contrast in Brazilian society since the already mentioned colonial and post colonial epochs. As the titles of his books suggest: The Masters and the Slaves, The Mansions and the Shanties, Order and Progress, these social categories found a common denominator within the Brazilian culture, a kind of living and conviviability within a spatial contiguity and so, they became a part of the eidos of Brazilian nationality.

There is no strong democratic tradition in Brazil in political terms. Since the outset of independence the political history of the country has been marked by military interventions,coups d'Etat, etc.; institutional stability being only exceptional moments of the Brazilian political chronicle. Authoritarianism was a diffused phenomenon in the nation. Schools, as a social institution, obviously suffer the impact of the cultural forces and tend to reflect such contradictions and distinct values.

\section{Some Methodological Considerations}

In the development of this study one can observe that both historical and systematic approaches have been used. Sometimes they appear almost simultaneously, interlacing ethnographical interpretations with philosophical and sociological theories and conceptions. The aim of applying a more broad and pluralistic methodology has two main reasons:

a) the conviction that it enriches the comprehension of the socio-

cultural phenomena, putting flesh and blood on the skeleton of some positivistic conceptions. The inspiration for such more open methodological perspective could be found in the works of such pragmatic philosophers as James and Dewey, in the Popperian criticism of historism, in some educational comparativists as Mallinson and Brian Holmes and on the foundations of the American Anthropology in which Franz Boas, as we will see in a moment, has an undisputed academic leadership;

b) to give coherence to the analytical ethnographical historical

approach of the Brazilian culture as developed in this paper, through the ideas of Gilberto Freyre.

Some considerations on this methodology should be preliminarily presented.

Freyre thought that the analysis of such cultural complexities go beyond the standards of the pure methodological and epistemological apparatus of the conventional scientific and social theories. Rather, in order to study a phenomenon like the Brazilian culture, it would be necessary to contrast the scientific laws resulting from theories and models of modern sciences with the incertitudes which come out of the complex cultural realities.

This relationship is by all means necessary, albeit momentarily, to activate the development and the progress of the social sciences and the knowledge (a kind ofDeweyan wisdom) of the human nature.

In this connection, Freyre proposed a multidisciplinary approach, a pluralistic interpretation of the Brazilian man and culture. This implied using, 
simultaneously, both the existing scientific tools and conceptions so far formally developed and the available contributions as they would come from historical, institutional, ethical and aesthetical resources. Only such approach would allow a better understanding of the nature, the character and the sentimentality of the Brazilian man and of the ingredients with which the nation was generated and historically created.

Human only can be explained through the human, even if one has to open a space to doubt and even to mysteryeven though conditionall ${ }^{3}$.

Gilberto Freyre's ideas also seem to find some roots in the foundation of Franz Boas' anthropology. Freyre was a former student of Boas at Columbia University. At that time, the Boasian conceptions were reaching their apogee and Freyre became influenced by them.

Although he himself has emphasized the originality of his work, the importance he gave to the ethnographic general approach fully supported by scientific and historical particular contributions of each culture, allow little doubts against the weight of such an influence.

Symptomatic, as well, is Freyre's own references to his former professor and the fundamental stimulations he provided to his academic work. As he had pointed out in the Preface to Master and Slaves:

Professor Boas is the model of Master who left upon me the greatest impression (...) I believe that no Russian student was as concerned about the destiny of Russia as I was concerned about the Brazilian future. It was as if all was depending upon me, upon our generation, searching for our ways of solving secular questiofs. ${ }^{4}$

The attempt at reconciling scientific methods and theories with the historical method of understanding, operated in Boas' conceptions as a corrective to go beyond the traditional uses of deductions and generalizations of laws from the phenomena.

This was one of Boas' great contributions to the Anthropological studies. Different from British Anthropology that moved in the direction of science and positivistic bias, the Boasian Anthropology was "both in origin and discovery a historical more than a logical problem. It could only be accomplished by getting behind appearances, transcending the point of view of the observer, and untangling the historical complexity of the process affecting human life to arrive at categories that were not found in the mind of the student but were somehow derived from, consistent with and in a sense internal to the phenomena themselves". ${ }^{54}$

\footnotetext{
${ }^{3}$ Freyre, Gilberto. Sobrado; e Mucambos. Rio de Janeiro: Jose Olympia, 1961, p. 351.

${ }^{4}$ Freyre, Gilberto. Casa Grande y Senzala.Venezuela: Biblioteca Ayacucho, 1977, p. 6.

${ }^{5}$ Stocking, George W. Jr. A Franz Boas Reader: The Shaping of an American Anthropology 1883-1911.
} 
These ideas seem to be profoundly stamped on Freyre's work. So, it was within this theoretical and methodological framework that he carried out an Anthropological study that attempted to make up an original historical and cultural contour for the formation of the Brazilian society. A systematic, criterous, exhaustive and careful description of the Brazilian cultural models, as Darcy Ribeiro observed, but in principle uninterested in theoretical generalizations ${ }^{6}$.

4. The Brazilian man's culture and social structural problems some interpretations

J. B. Gitter in analyzing the problem of human nature ${ }^{76}$ makes a very important distinction between human social nature and human cultural nature. The former being derived from experiences in primary groups, i.e., those inner traits of human personality which result from man's more natural and spontaneous interactions with his fellows and his environment; the latter being originated from experiences developed in secondary groups, namely, those already socially institutionalized.

Connected to this distinction it is important to observe in the history of the Brazilian traditional society that, since the advent of the colonial era, due to the size of the Brazilian territory and the scarcity of the colonizer's population, there occurred a practical impossibility of establishing effective forms of territorial and social control and easy communication.

The development of isolated communities started having mainly

the family as the nuclear pattern of social, political and economic organization. As social groups these communities were economically organized on the basis of extensive monocultures, having sugar-and later coffee as their economic basis, the landlord being, within this system, the absolute authority. In fact, they were

the "longa manus" of the Portuguese State exercising the social control and establishing the basis upon which the incipient Brazilian social structure was forged.

Laws and rules of behaving and the status and roles developed by the racial groups involved in these interactions were all under control and arbitration of the "paterfamilias" and later historically reproduced through other similar individual and familiar structures of power.

It was this historical way of settling the Brazilian social groups, with weak ties with the formal social structure of the Portuguese government, which by conjunctural reasons left in the hands of individual citizens the

The Univ. of Chicago Press 1982.

${ }^{6}$ cf. Freyre 1977 op. cit., p. XX.

${ }^{7}$ Bottomore, T B.Sociology. George Allen \& Winwind, London 1971, p. 290-310. Gitler's terminology, as presented above, seem.to be apparently opposite to the use of the tenn culture as it i_employed in the present analysis. However it is only a nominalistic problem. in Gitler's sense, social nature is spontaneous, instinctively institutionalized, forms oflifc not rationally organized, while cultural nature abridges social interactions which are instituitionally and bureaucratically organized as a result of a process of civili7.ation. So, in meaning and contents the distinction is compatible with and serves the purpose of this study. 
economic and territorial control of the colony. It was at that moment as well, that the primitive individual and social ways of thinking, valuing and behaving seem to have been delineated.

The length of time, the historical and cultural duration of these primitive cultural patterns seem to constitute one of the first problems related to the slowness with the pathways of the cultural evolution from original to institutional forms of social life.

When the civilization process was progressively introduced with the civilization of the formal Monarchic and later the Republican State, when new forms of acculturation were then incorporated to such structure, one had a kind of interpolated superstructure which at the same time, as we will soon see, interacted and conflicted with those primordial segments.

The social life of Brazil, its peculiarities and dilemmas have been interpreted both in their etiology and early cultural developments through historical and anthropological analysis as that elaborated by Gilberto Freyre.

Other systematic and modem formulations have tried to explain the Brazilian social problems and develop new models to transform the existing reality. These latter theoretical constructs are supported by the premises on which the coherence and applicability of them depend upon. So, deductions from these premises are necessary conditions to the logicality and practicability of those conceptions. Relations in the way of producing (economy) as those concerned with thecnical and scientific modernization of society, for instance, constitute some of these essential premises. Modification in those relations, therefore, will affect the social structure and promote the desired social changes they aim to fulfill.

In this study, Freyre's model, particularly as related to thecultural ingredients he identifies in the origin and early evolution of Brazilian society (raw elements) will be contrasted with those already elaborated in the institutional fabric of the existing social structure and the constituents of the civilization process (cooked elements). In these circumstances it seems to be possible to compare those particular explanations of the Brazilian social problems and see which of them, in part or as a whole, would explain better these problems and which obstacles have acted as barriers against social changes. It seems to be possible as well to shed some light on the theoretical and social legitimacy of those particular explanations of the Brazilian social problems and see which of them, in part or as a whole, would explain better these problems and which obstacles have acted as barriers against social changes. It seems to be possible as well to shed some light on the theoretical and social legitimacy of those models under analysis.

\section{Final Note}

These interpretations, as well as the ideological commitments imbricated in some of them, will next be briefly presented and discussed.

I. Gilberto Freyre described and interpreted Brazilian society as a peculiar model of social integration and an example of ethnical and cultural pluralism.

He saw the mixed Brazilian culture, fusing Europeans, Africans and Indians, as a positive and most distinctive aspect of the Brazilian man and culture. He believed 
that the cultural problem could not be properly explained as a product of races and hereditary reasons. It is rather a synthesis of environmental and cultural legacies, historical and psychological components which were in the background of the Brazilian colonization and that played a fundamental role in the determination of the nation's culture and personality.

Cultural crisis would occur when tradition no longer conforms to values and practices of scientific and technological progress. The accommodation of some essentials of the Brazilian culture to them, therefore, no matter how far the country is to be engaged in modernization and development, would be necessary to allow the continuity of a functional "devenir" of the nation.

In explaining the causes that are at the bottom of the Portuguese colonization,

Freyre, among others, emphasized that the military and technical domination of Indians and Negroes by the Portuguese Europeans encouraged the latter to tolerate and make concessions to the former in terms of sexual, labor and social relationships. The lack of white women, for instance, among the Portuguese Europeans themselves, opened space to more easy and natural intercourse between dominant and dominated people.

The sexual relationships between white man and women from the other races, notwithstanding being, in the majority of the cases, one of the superiors with inferiors, one of despotic sadistic Lords with passive Slaves, were mitigated due to the colonizer's need of constituting within such circumstances and basis ${ }^{8}$

The catholic doctrine and the conditions upon which it was historically developed, assimilated, interpreted and translated into the Portuguese nation and culture was another fundamental element to the understanding of the Brazilian colonization.

A kind of religious syncretism had emerged in Portugal, revious to the Brazilian colonization, from the interweaving of Roman Catholicism and Mohammedanism, the consequence being, in religious and social terms, the assimilation of certain mystical traits of the moslem religion and culture by the existing Catholicism.

Effects of this interlacing were also felt, on the other hand, in the moslem's pragmatical nature of dealing with business and agricultural techniques, as well as in language, customs, and particularly in the slavery system which was a domestic rather than an industrial one. Reproduction of this syncretism was portrayed in the Portuguese colonization in Brasil. As Freyre himself explained the roots of the slavery system in Brazil:

it was different from the Anglo-American, the Dutch and even the French and the Spanish systems of modern slavery. It was an extension of the Portuguese system just as the Portuguese system was an extension of the Moorish or Arab or Mohammedan system of domestic rather than industrial slavery.( ... ) we know that the Portuguese, though intensely Christian and, more than that

\footnotetext{
${ }^{8}$ Freyre 1977, op. cit.. p. 8.
} 
champions of the cause of Christianity against the cause of Islam, imitated Arabs, the Moors and the Mohammedans in a nurnberofthecniques and customs, and assimilated from them a number of cultural values. The Mohammedan conception of Slavery, as a domestic system linked to family organization as a whole and including economic activity without being ellfirely dominated by an economic industrial purpose, was one of the Moorish values that the Portuguese applied to their christian colonization to Brazil. ${ }^{9}$

He concluded affinning that the Mohammedans had for centuries been superior to the Europeans and Christians in their methods of assimilating African groups and cultures into their civilization. And, to give substance to his argument he quoted Professor Fox Pitt-Rivers, a British Anthropologist who supported that "Orient slavery is something quite different, nobler and less degrading than it was in Europe and the United States." 10

Mohammedan education also left, according to Freyre, some of its traits in the Brazilian culture. The way children in the 19 'h century recited in concert the multiplication table and their spelling lessons reminded him of Mohammedan schools. ${ }^{11}$

In religious terms, one could observe later in Brazil the amalgamation of Negro sects and culture with the official Catholicism." Integration of different patterns of culture equally happened between Christians and Jews, bringing about remarkable influences in the formation of the Portuguese culture. Influences that were reflected in the area of commerce, in the tendency toward financial speculations aiming at high profits, as well as in the administration and the development of scientific and technological knowledge.

Another important effect of this cultural interaction which underlies the Portuguese mercantilist and slavery character - lately also leaving in the Brazilian colonial and post colonial periods a profound impact-was the antipathy towards all kinds of manual work and the fascination for diplomas, bachelorship, legalism and juridical mysticism.

Intermarriages between Portuguese and Jews were not uncommon, binding together-no matter what the blood origins may have beenfamilies, many of them influential both in economic and political terms.

All these socio-cultural events, despite their relevancies and weaknesses, operated within the Portuguese culture and society with a singular functionality. So, in relation to this unique social phenomenon of Jew and Portuguese's easier racial integration some analysts have observed, for instance, that while the Jews, everywhere, developed a consciousness of race, this however was not true in Portugal. There, Jews became more integrated to the social system and culture. Catholicism in Portugal-they explained-was not properly

\footnotetext{
${ }^{9}$ Freyre, Gilberto.New World in the Tropics(The Culture of Modern Brazil). New York: Vintage Books, J963.p.197-198.

${ }^{10}$ Freyre 1963.op. cit.. p. 199

${ }^{11}$ Freyre 1977,op.cit.,p.218.
} 
concerned with the purity and the preservation of race as other Europeans conquerors were. Rather, the Portuguese were much more worried over the purity of faith.

Analogously to what was earlier stated, one could observe that as a result of these symbiotic interrelations, economic and political interests as well as religious aims, were deeply interlaced in Portugal, finding here confluences, there conflicts but always new ways of conviviality. The intense and long contact of Portuguese with the Arabs, the Moors, and the Jews was an "integration or balance, of contending elements rather than segregation or sharp differentiation of any of them or violent conflict between them" and, as Freyre pointed out, the impact of the crashing among these distinct cultural forces in the Portuguese life and its colonial enterprises was decisive since:

For the preservation of such healthy differences or antagonism, it was a good thing that the forces for uniformity did not always act together, but were sometimes competitive and antagonistic: the Crown, against the Church, for instance, the Society of Jesus against the Inquisition. There was a period when the Jews themselves had the Jesuits as their protector against the powerful Inquisition. ${ }^{12}$

In educational terms, the bases of the Brazilian colonial instruction were decisively set up and conducted by the Portuguese Jesuit order. (The Jesuits were officially and really responsible for the whole Brazilian education for more than two centuries). Their humanistic trends, their taste for manner of discussing and solving problems, their taste for literary, memorialistic and pure intellectualistic studies were considered by Freyre as too formal and, therefore, to a great extent, not compatible with the psychology and interests of the aborigines." 13

Freyre thought that the Franciscans would have been a better option for the Brazilian men and environment. They possessed much more things in common with the aborigines:

The Franciscans were, above all concerned with turning the natives into artisans and technicians: they avoided overburdening them with that mental exertion which the Indians hated more than manual labor ${ }^{14}$

while the Jesuits

came here without any purpose of developing technical or artistic activities among savages, but rather those of a literary and academic

\footnotetext{
${ }^{12}$ Freyre 1963, op. cit., p. 45.

${ }^{13}$ Freyre 1977, op. cit., p. 154.156.

${ }^{14}$ Freyre 1977, op. cit., p. 159.
} 


$$
\text { nature. }{ }^{15}
$$

However, it is in the phenomenon of the Brazilian racial miscegenation that Freyre found out one of the positive values which influenced the development of the colonial education. He illustrated this assertion stating that:

Not only were black and mulattoes in Brazil the companions of white lads in the Big Houses, schoolrooms and in colleges, there were also white boys who learned to read with Negro teachers. ${ }^{16}$

If one looks at Freyre's ethnographical theory as it has been presented so far it is possible to derive a special focus on education. This focus is not properly centered on organized education as it developed in modem societies but more as a natural and pragmatic process which intersperses in every day life its values.This kind of education would be able to allow the transformative encounter between the old and the new on the line of an organic social evolution itself.

\footnotetext{
${ }^{15}$ Freyre 1977, op. cil p. 159. 160.

${ }^{16}$ Freyre 1977, op. cit., p. 409.
} 